\title{
Healthcare systems within the Middle East
}

\author{
Elizabeth Dent, Damilola Toki, Natalie Dupuis, Josiah Marquis, Tharmitha Suyeshkumar, Meriem Benlamri \\ Faculty Reviewer: Lloy Wylie, PhD, MA (Department of Psychiatry)
}

\begin{abstract}
Diverse health systems within the Middle East continue to experience a high degree of variability with regards to accessibility, capacity, and the quality of care provided within each individual country. This paper summarizes the unique challenges and achievements within the healthcare systems of six countries in the Middle East region. Additionally, the review aims to provide evidence for how healthcare systems in the Middle East are managed and sustained despite differences in wealth and infrastructure, as well as the presence of conflict in certain areas. Canada can play an important role in supporting these countries with unique healthcare needs, and in supporting populations arriving to Canada from these countries.
\end{abstract}

\section{INTRODUCTION}

Healthcare systems around the world are constantly evolving in order to adapt to new challenges presented by changes in the environment, disease patterns, demographics, and a myriad of other factors that may affect the delivery of healthcare services. Many factors have a direct impact on local health systems, including a country's wealth, population size, human resource capacity, and exposure to conflict. ${ }^{2}$ This paper will illustrate the heterogeneity of healthcare systems across the Middle East by profiling six countries. The countries included are Oman, United Arab Emirates (UAE), Egypt, Lebanon, Palestine, and Yemen.

These countries share a similar two-tiered healthcare system structure, with both public and private streams of financing and service delivery. However, there is a great deal of variability of public and private insurance coverage within a given population, as well as the amount of cost-sharing that may be required for public health services. There is a significant range in amount of government funds allocated towards healthcare across the region. For example, Oman is considered to be at the higher end of the range, where the healthcare system is $82 \%$ government funded. Meanwhile, Yemen's healthcare system is only $28 \%$ government funded., ${ }^{1,3}$ In terms of infrastructure and organization, health service delivery across the region varies greatly. Oman has a centralized system, whereas the remaining five countries are considered to have a decentralized service delivery organization.

As the world becomes more globalized and conflicts around the world cause vast migrations of people from one continent to the next, Canada can learn from international health systems such as those in the Middle East in order to prepare for the challenges that may arise abroad and at home. An awareness of the various vulnerabilities that can affect a citizen's health is the first step towards building a resilient health system, and by observing others this awareness can occur much faster.

\section{OIL WEALTH}

The Persian Gulf states of the Middle East, including the relatively small populations of Oman and the UAE, acquire significant wealth from the oil industry. ${ }^{2}$ The wealth attained by these oil-producing countries allows them to allocate significant amounts of resources towards their healthcare systems, providing a means to further develop their physical infrastructure, healthcare training programs, and healthcare administration capabilities. ${ }^{2}$ Additionally, this wealth provides opportunities of forming partnerships at an international level. These conditions have allowed the UAE to strive to become a global leader in healthcare, whereby efforts to advance the current health system include improvements to information technology infrastructure and enhancing integration of services throughout the Emirates. ${ }^{4}$ These attributes are driving forces behind the creation of effective health systems within the Persian Gulf region, which will continue to play a role in improving the health of citizens living within this region. ${ }^{4}$

\section{ADEQUATE INFRASTRUCTURE AND SOCIAL DETERMINANTS OF HEALTH}

Countries with minimal financial resources and larger populations, such as Egypt and Lebanon, often have sufficient infrastructure, healthcare professionals, and other resources required to adequately support the delivery of health services in the population. ${ }^{2}$ Unfortunately, these healthcare systems often result in health service inequities due to the significant effects of the social determinants of health, including family income, insurance coverage, education, gender, and geographical location, which result in a wide array of negative long-term health outcomes. ${ }^{5}$ In Egypt, an individuals ability to access health insurance and high-quality health services is heavily influenced by their financial status and income. ${ }^{5}$ Therefore, an individual who lacks financial resources will ultimately find themselves with a reduced quality of healthcare. This is the case for $55 \%$ of the population, whereby uninsured citizens must exclusively pay out-of-pocket when accessing healthcare services. ${ }^{1}$

Many of these countries continue to face additional burdens on their healthcare system from the high influx of refugees fleeing from nearby conflict zones, as seen in Lebanon. An approximate 4.6 million residents live in Lebanon, including over one million Palestinian and Syrian refugees who have sought refuge from conflicts. ${ }^{6}$ This has led to significant instability within Lebanon, both structurally and socially, which has negatively influenced access to high quality healthcare services. ${ }^{1}$ With an already overstretched healthcare system, utilization of primary healthcare centers for maternal and child health-related services has increased by approximately $50 \%$ since the Syrian refugee crisis in recent years. ${ }^{6}$ Although there are ongoing international efforts in supporting the Syrian and Pal- 
estinian refugees currently residing with Lebanon, contributions are far from being sufficient enough to provide coverage of healthcare services for all individuals residing within the country in an equitable manner. ${ }^{6}$

\section{WAR AND CONFLICT}

Countries that are currently involved in war or conflict experience unique and severe complications within their health system. Examples include Palestine and Yemen, although other Middle Eastern countries have also experienced similar effects since the Second World War. ${ }^{2}$ Conflicts in these countries have placed a great deal of stress on healthcare systems, affecting infrastructure, organization, financing, and human resources. For example, the civil war that has resulted in Yemen over the years has led to only $45 \%$ of the 3507 healthcare facilities within the country to be fully functional. ${ }^{7}$ Additionally, since only $28 \%$ of healthcare financing comes from government, Yemen cannot provide full health coverage to its citizens, resulting in cost-sharing and community health insurance initiatives. ${ }^{1}$ Within this region, hospitals and healthcare professions have often been the targets of conflict, thus resulting in a high degree of uncertainty regarding the safety of seeking healthcare services and their availability to citizens. ${ }^{8}$

The geopolitical context in Palestine results in limited freedom of movement and economic stability due to Israeli occupation. Such factors introduce major challenges for the maintenance of health for the Palestinian population. ${ }^{9}$ Additionally, a lack of political unity in Palestine leads to the exacerbation of inaccessibly to high-quality health care services, which already exist due to imposed territorial segregation. ${ }^{10}$ Due to years of political instability and conflict, large waves of Palestinian refugees have escaped to nearby countries. For the population that remains in Palestine, the UN Relief and Works Agency, the Ministry of Health, Hamas, NGOs, and private sector players have been responsible for administering healthcare services to Palestinians within Gaza and the West Bank regions. ${ }^{11}$

\section{CONCLUSION}

There are many important factors to consider when creating and maintaining a robust healthcare system within a country. The highest quality of care appears to be a direct result of sufficient finances, adequate infrastructure, exceptional governance, and social stability within the country. There will continue to be significant challenges to accessing quality care for populations throughout the Middle East as a result of politics, past and current conflicts, lack of financial resources, physical and social environments, and the negative outcomes that are derived from inaccessible medical treatments and healthcare services. These intersectional factors create unique and complex challenges to ensuring a high quality of life for residents. By addressing current issues at national and international levels, with particular focus on the governance, organization, and financing of health services, opportunities for successful interventions can be created and implemented.

In a similar manner to the Canadian context, anticipating evolving healthcare needs and appropriately planning and investing in the future of the system is vital. As stakeholders of the Canadian healthcare system, we must remain aware of the vulnerabilities that exist for incoming refugees that result due to previous exposures to war, conflict, social instability, and consequent unmet health needs. By adopting a health equity lens and working with the populations we serve, we must move towards reducing health disparities and improving overall quality of life for vulnerable individuals who arrive in Canada.

\section{REFERENCES}

1. WHO. Health System Profile: Yemen. EMRO [Internet]. 2006 [Cited 14 Jan 2017]. Available from: http://apps.who.int/medicinedocs/documents/s17314e/s17314e.pdf.

2. Parkash J, Younis MZ, Ward W. Healthcare for the Ageing Populations of Countries of Middle East and North Africa. Ageing International. 2015; 40(1).

3. Alshishtawy MM. Four Decades of Progress, Evolution of the Health System in Oman. Sultan Qaboos University Medical Journal. 2010; 10(1).

4. US-U.A.E. Business Council. The U.A.E Healthcare Sector Report. [Internet]. 2010 [14 Jan 2017]. Available from: http://usuaebusiness.org/ wp-content/uploads/2014/06/HealthcareReport_Update_June2014. pdf.

5. WHO. Health System Profile: Egypt. EMRO [Internet]. 2006 [Cited 14 Jan 2017]. Available from: http://apps.who.int/medicinedocs/documents/s17293e/s17293e.pdf.

6. WHO. Lebanon. Country Cooperation Strategy at a Glance [Internet]. 2014 [Cited 25 Jan 2017]. Available from: http://apps.who.int/iris/bitstream/10665/136909/1/ccsbrief_lbn_en.pdf.

7. WHO. Health system in Yemen Infographic [Internet]. 2016 [Cited 14 Jan 2017]. Available from: http://reliefweb.int/sites/reliefweb.int/files/ resources/yemen-herams-infographic-november2016.pdf.

8. Moszynski P. Attacks on Doctors in the Middle East Need to be Investigated. BMJ. 2011; 342(7799).

9. Vitullo A, Soboh A, Oskarsson J et al. Barriers to the Access to Health Services in the Occupied Palestinian Territory: A Cohort Study.The Lancet. 2012; 380 .

10. Bhaiwala Z. Health Under Occupation: Constraints on Access to Healthcare in the Palestinian Territories [Internet]. 2015 [Cited 14 Jan 2017]. Available from: http://mondoweiss.net/2015/08/constraints-palestinian-territories/.

11. Schoenbaum M, Afifi AK, Deckelbaum RJ. Strengthening the Palestinian Health System (Rep.). Santa Monica, CA: RAND Corporation. 2005 [Cited 14 Jan 2017]. 